\title{
Bubble CPAP for Respiratory distress in Neonate
}

\author{
Aulakh R ${ }^{1}$ \\ ${ }^{1}$ Dr. Roosy Aulakh, Associate Prof, Dept. of Pediatrics, Govt. Medical College \& Hospital, Sector 32, Chandigarh, India.
} Address for correspondence: Email: drroosy@ gmail.com

\begin{abstract}
Respiratory Distress Syndrome is a major contributor towards Neonatal Mortality Rate. Effective ventilation strategies which are safe, effective and low cost are required to manage neonates with Respiratory Distress Syndrome in resource limited low and middle income countries. Bubble Continuous Positive Airway Pressure has emerged recently as one such alternative.
\end{abstract}

Keywords: Neonatal Mortality Rate, Respiratory Distress Syndrome, Bubble Continuous Positive Airway Pressure

In $2015,2.7$ million deaths, or roughly $45 \%$ of all under-five deaths occurred during neonatal period, the most vulnerable period for child's survival [1]. Worldwide, Respiratory Distress Syndrome (RDS) is a major contributor towards Neonatal Mortality. Provision of low cost, effective and easily implementable respiratory support methods is urgently required, especially in developing countries. Bubble continuous positive airway pressure (bCPAP) has recently emerged as one such alternative.

Bubble CPAP, introduced almost 40 years back, is a non-invasive nasal CPAP delivering system. With this method, blended and humidified oxygen is delivered via nasal prongs and pressure in the circuit is maintained by immersing the distal end of the expiratory tubing in water.

CPAP delivered by this underwater seal causes vibration of the chest due to gas flow under water; and these vibrations simulate waveforms produced by high frequency ventilation.

With the combined effects of optimal humidity and natural pressure oscillations, bubble CPAP provides a protective, safe and effective method of respiratory support to spontaneously breathing neonates.

Various studies have confirmed the efficacy of bCPAP in managing neonates with respiratory distress. Lee et al demonstrated the superiority of B-CPAP as compared to V-CPAP in premature infants [2]. Nowadzky $\mathrm{T}$ et al showed that the use of B-CPAP reduces the need for mechanical ventilation among very low birth weight infants with RDS [3].

Major advantage of bCPAP is its potential for use in resource limited settings. Various studies have recently explored this potential benefit of bCPAP. A systematic review on efficacy and safety of bubble CPAP in neonatal care in low and middle income countries by Martin S et al concluded that bubble CPAP is safe and reduces the need for mechanical ventilation in neonates with respiratory distress [4].

A recent randomized controlled trial of flow driver (FD) and bubble continuous positive airway pressure in preterm infants in a resource-limited setting found bCPAP equivalent to FD CPAP in the total number of days receiving CPAP within a margin of 2 days [5]. Myhre $\mathrm{J}$ et al reported significant contribution of bCPAP to favorable outcomes for preterm infants with RDS in rural African hospital [6].

The first extensive survey performed in a large NICU from a low-middle income countries, confirmed the efficacy of the systematic use of a bNCPAP device in reducing newborn mortality [7].

A recent study in this issue by Jain $\mathrm{H}$ et al highlighted that indigenous bCPAP is an effective and non-invasive way to provide ventilation in a setup with limited resources. It can be used to manage respiratory distress 
due to RDS, congenital pneumonia \& meconium aspiration syndrome [8].

Progress in reducing Neonatal Mortality Rate is closely linked to improvements in the management of respiratory distress in preterm infants. Current modalities of respiratory support in neonates with RDS include mechanical ventilation and continuous positive airway pressure.

Recently, a number of studies have highlighted the role of non invasive nasal CPAP in managing RDS in neonates. Bubble CPAP has emerged as a low cost, safe and effective method of CPAP delivery to neonates with RDS, especially in resource limited low and middle income countries.

\section{Funding: Nil, Conflict of interest: Nil \\ Permission from IRB: Yes}

\section{References}

1. Global Health Observatory (GHO) data. World Health Statistics 2016. Available at http://www.who.int/gho/child_health/mortality/neonatal _text/en/. Accessed on 11/06/2016.

2. Lee KS, Dunn MS, Fenwick M, Shennan AT. A comparison of underwater bubble continuous positive airway pressure with ventilator-derived continuous positive airway pressure in premature neonates ready for extubation. Biol Neonate. 1998;73(2):6975. [PubMed]
3. Nowadzky T, Pantoja A, Britton JR. Bubble Continuous Positive Airway Pressure, A potentially better practice, reduces the use of mechanical ventilation among very low birth weight infants with respiratory distress syndrome. Pediatrics. 2009;123(6):1534-40. [PubMed]

4. Martin S, Duke T, Davis P. Efficacy and safety of bubble CPAP in neonatal care in low and middle income countries: a systematic review. Arch Dis Child Fetal Neonatal Ed. 2014 Nov;99(6). [PubMed]

5. Mazmanyan P, Mellor K, Doré CJ, Modi N. A randomised controlled trial of flow driver and bubble continuous positive airway pressure in preterm infants in a resource-limited setting. Arch Dis Child Fetal Neonatal Ed. 2016 Jan;101(1):F16-20.

6. Myhre J, Immaculate M, Okeyo B, Anand M et al. Effect of Treatment of Premature Infants with Respiratory Distress Using Low-cost Bubble CPAP in a Rural African Hospital. J Trop Pediatr. 2016 Apr 25. [PubMed]

7. Rezzonico R, Caccamo LM, Manfredini V, Cartabia $\mathrm{M}$ et al. Impact of the systematic introduction of lowcost bubble nasal CPAP in a NICU of a developing country: a prospective pre- and post-intervention study. BMC Pediatr. 2015 Mar 25;15:26. [PubMed]

8. Jain H, Arya S, Mandloi R, Menon S. To study the effectiveness of indigenous bubble CPAP in management of respiratory distress in newborns. Paed Rev: Int J Pediatr Res 2016;3(5):291-294.

\section{How to cite this article?}

Aulakh R, Gedam DS. Bubble CPAP for Respiratory distress in Neonate. Paed Rev: Int J Pediatr Res 2016;3(5):283284.doi:10.17511/ijpr.2016.i05.01 